研 究

\title{
リチウム亜鉛フェライトの複素透磁率スペクトル
}

\author{
宮本 剛, 中村 龍哉, 山田 義博 \\ 姫路工業大学大学院工学研究科電気系工学専攻, 干 671-2201 姫路市書写 2167 .
}

\section{Complex Permeability Spectra of Polycrystalline Li-Zn Ferrites}

\author{
Tsuyoshi Miyamoto, Tatsuya Nakamura and Yoshihiro Yamada \\ Department of Electrical Engineering and Computer Sciences, Graduate School of Engineering, Himeji Institute of Technology, \\ 2167 Shosha, Himeji 671-2201.
}

Received March 11, 2003

\begin{abstract}
SYNOPSIS
Polycrystalline $\mathrm{Li}-\mathrm{Zn}$ ferrites were prepared by the ceramic sintering method, and their complex permeability spectra were measured. The low-frequency permeability decreased with an increase in the Li-ferrite fraction. However, the natural resonance frequency shifted higher when the fraction of $\mathrm{Li}$-ferrite was increased. According to our previous model, the complex permeability spectra were numerically separated into spin rotation and domain wall motion contributions. For the spin rotational component, which played an important role in the high frequency region, the static spin susceptibility decreased and the spin resonance frequency shifted higher with an increase in the $\mathrm{Li}$-ferrite fraction. The product values of the static spin susceptibility and the spin resonance frequency, corresponding to the Snoek's product value, took a maximum value at a certain fraction of Li-ferrite. This was reflected to the performance of the single layered electromagnetic wave absorber using the polycrystalline ferrites.

KEY WORDS
\end{abstract}

Ferrite, complex permeability, spin rotational component, Snoek's product, EM-wave absorber

\section{1 緒 言}

フェライトの誘電率および透磁率は周波数に依存する.多 結晶フェライトの複素透磁率スペクトルには自然共鳴が存在 ( ${ }^{1-3)}$, 高周波領域での透磁率スペクトルに制限を加えている. これはスヌークの限界則として知られているものである゙).

複素透磁率スペクトルは磁化過程と密接に関係している.

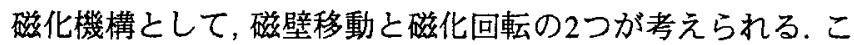
れまでの我々の研究で5-7，複素透磁率スペクトルは，磁壁移 動成分と磁化回転成分に分離でき， $100 \mathrm{MHz}$ 以上の高い周波 数領域では, 主に磁化回転成分で決定されることが分かった。 さらに，磁化回転成分のパラメータからスヌーク限界則に対 応する值を定義できることも分かった。

本研究では，スピネル型フェライトの中で，比較的磁化の 大きい Li-Zn フェライトを取り上げた. スヌーク限界則の観 点から複素透磁率スペクトルを考察し，他のスピネルフェラ イトの結果と比較を行った. さらに, Li-Znフェライトを用い た単層型電磁波吸収体への忘用を検討した。

\section{2 試料の作製および実験方法}

Li- $Z n$ フェライトは, 固相反応法により作製した. 出発原料 として $\mathrm{Li}_{2} \mathrm{CO}_{3}, \mathrm{ZnO}$ および $\mathrm{Fe}_{2} \mathrm{O}_{3}$ を, 化学組成が $\mathrm{Li}_{0.5 x} \mathrm{Zn}_{1-X}$ $\mathrm{Fe}_{2+0.5 x} \mathrm{O}_{4}(X=0.3 \sim 0.8)$ となるように秤量，混合した．混合粉 末各 $10 \mathrm{~g}$ をプレス成型し， $900^{\circ} \mathrm{C}$ で5時間仮焼した。 その後， 粒子径が $1 \mathrm{~mm}$ 以下になるまで粗粉研し，さらにこの粉末を湿 式法により微粉碎した. 得られた粉末を再度プレス成型し， この成型体を $1150^{\circ} \mathrm{C} て ゙ 5$ 時間焼結させた. 走査型電子顕微鏡 (JEOL, JSM-S310)を用いて，多結晶フエライトの微細構造を 観察した．振動試料型磁力計(TOEI KOGYO, VSM-5)を用い て，フェライト焼結体の磁化を測定した。透磁率を測定する ために，超音波加工機(日本電子工業UM-300C) を用いて，外 径 $7 \mathrm{~mm}$ ，内径 $3 \mathrm{~mm}$ のリング状サンプルを作製した．周波数 $100 \mathrm{kHz}$ から $100 \mathrm{MHz}$ の複素透磁率は, インピーダンスアナラ イザー(Hewlett Packard, HP-4194A) を用いて，周波数 $50 \mathrm{MHz}$ から $6 \mathrm{GHz}$ の複素透磁率は，ネットワークアナライザーを用 いて測定した. 


\section{3 実験結果および考察}

粉末 X線回折の結果, 焼結体サンプルはいずれもスピネル 単相であり, Nelson-Relay法により求めた格子定数は, Li-フェ ライトの含有率Xの隇少とともに直線的に減少し, Vegard則 に従っていることが分かった．焼結体の相対比重は組成によ らず，いずれも 95\%以上であり，緻密な焼結体サンプルが得 られた. SEM観察より，粒子サイズは平均して約 $5 \mu \mathrm{m} て ゙ あ り ，$ 組成によらずほぼ一定であった. 磁化の值は, Xの増加ととも に増大し， $X=0.75$ で最大値をとった後，わずかに減少した. この変化の様子は, collinear スピン構造から Yafet-Kittel三角 スピン構造へのスピン構造の変化と, ネール点の変化から説 明できると思われる。

Fig.1に，今回作製した多結晶フエライトの複素透磁率スペ クトル $\left(\mu=\mu^{\prime}-\mathrm{j} \mu ”\right)$ を示す.これは典型的な自然共鳴のスペ クトルである. 約 $2 \mathrm{MHz}$ 以下の低周波数帯での $\mu^{\prime}$ は，Xの増 加とともに減少した. 一方，約 $300 \mathrm{MHz}$ 以上の高周波数帯で の $\mu^{\prime}$ は，Xの増加とともに增加した. $\mu$ ”が最大となる自然共 鳴周波数は, Xの増加とともに, $2 \mathrm{MHz}$ から $25 \mathrm{MHz}$ へと高周 波側にシフトした。

これまでの研究から，多結晶フェライトの複素透磁率スペ クトルは，以下のようにして共鳴型で周波数の 2 乗に逆比例 する磁壁移動成分 $\chi_{\mathrm{sp}}(\omega)$ と, 散晩係数が非常に大きく, 周波 数に反比例した緩和型となる磁化回転成分 $\chi_{\mathrm{dw}}(\omega)$ に数值的に 分離できることが分かっている 以下のようにあらわすことができる.

$$
\begin{aligned}
& \mu(\omega)=1+\chi_{\mathrm{sp}}(\omega)+\chi_{\mathrm{dw}}(\omega), \\
& \chi_{\mathrm{sp}}(\omega)=K_{\mathrm{sp}} /\left[1+j\left(\omega / \omega_{\mathrm{sp}}\right)\right], \\
& \chi_{\mathrm{dw}}(\omega)=K_{\mathrm{dw}} \omega_{\mathrm{dw}}^{2} /\left[\omega_{\mathrm{dw}}^{2}-\omega^{2}+\mathrm{j} \beta \omega\right] .
\end{aligned}
$$

ここで, $\omega$ は外部磁界周波数， $K_{\mathrm{sp}}$ は静的回転磁化率， $\omega_{\mathrm{sp}}$ は磁

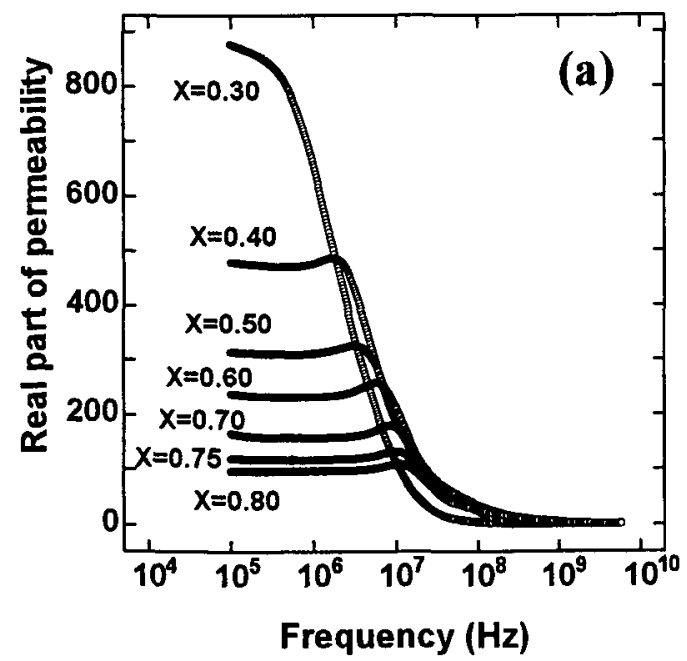

化回転共鳴周波数， $K_{\mathrm{dw}}$ は磁壁移動の静的磁化率， $\omega_{\mathrm{dw}}$ は磁壁 移動共鳴周波数, $\beta$ は磁壁移動の減衰摩擦係数である. 磁壁移 動による磁化率は低い周波数で減少し，高周波領域では，周 波数に対する依存性の違いから磁化回転成分の奇与が極めて 大きくなる. ゆえに，100MHz以上の高い周波数領域の透磁 率は，主に磁化回転成分で決まることが分かっている。

式(1)〜(3)を実験で得られたLi-Znフェライトの複素透磁率 スペクトルに適用し，各成分のパラメータを数值的に決定し た. 以下では，100 MHz 以上の高い周波数領域で主な働きを 示す磁化回転成分のパラメータのみを議論する. 磁化回転成 分の各パラメータの化学組成 Xに対する変化を Fig. 2 に示す. この図より, 静的回転磁化率 $K_{\mathrm{sp}}$ は Li- フェライトの含有量 $X$ の増加とともに減少し, 磁化回転共鳴周波数 $\omega_{\mathrm{sp}}$ は $X$ の増加と ともに高周波側へシフトすることが分かる.これらの $K_{\mathrm{sp}}$ と $\omega_{\mathrm{sp}}$

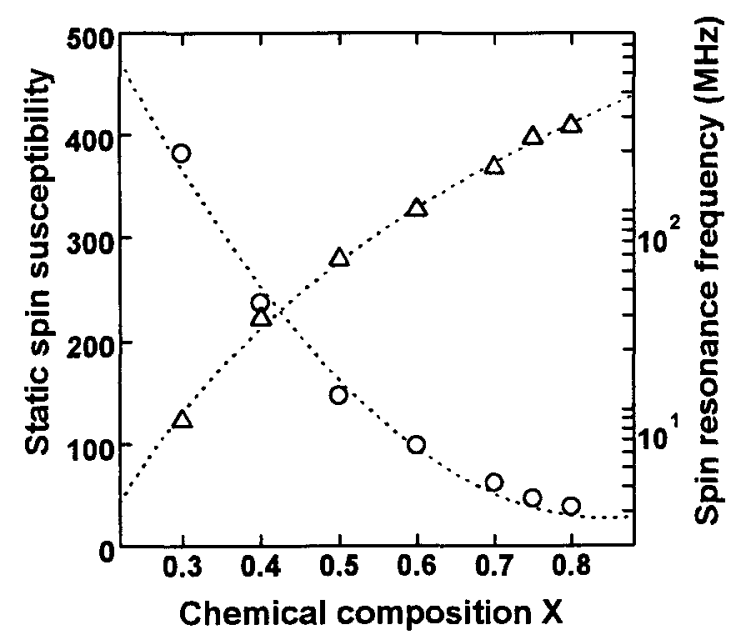

Fig.2 The variations of static spin susceptibility (open circle) and spin resonance frequency (open triangle) with the chemical composition of polycrystalline $\mathrm{Li}-\mathrm{Zn}$ ferrite, $\mathrm{Li}_{0.5 x} \mathrm{Zn}_{1-x}$ $\mathrm{Fe}_{2+0.5 x} \mathrm{O}_{4}$.

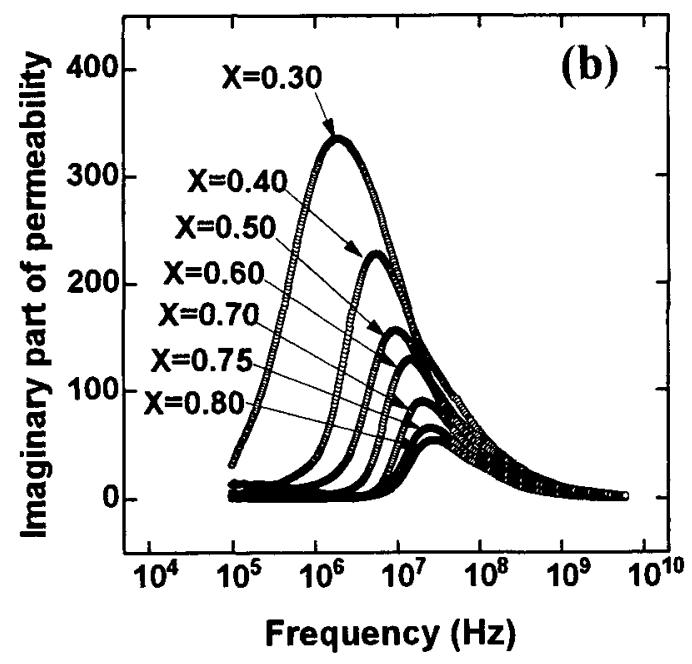

Fig.1 The complex permeability spectra of polycrystalline $\mathrm{Li}-\mathrm{Zn}$ ferrite, $\mathrm{Li}_{0.5 x} \mathrm{Zn}_{1-x} \mathrm{Fe}_{2+0.5 x} \mathrm{O}_{4}$, with the chemical composition $X$ : (a) real and (b) imaginary parts. 
の組成による変化は，低周波数での透磁率と自然共鳴周波数 の変化に各々対応している.

静的回転磁化率と磁化回転共鳴周波数の積はスヌーク積に 对応するものであることが分かっている. そこで, Li-Znフエ ライトのスヌーク櫴を計算し, 化学組成Xの関数として Fig.3 に示す.スヌーク樌の值は，Xの増加とともに增加し， $X=0.75$ で最大值をとり，その後わずかに減少した．さらに，Fig.4に 磁束密度とスヌーク積の関保を示す．この図には，他の多結

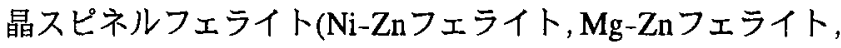
$\mathrm{Ni}-\mathrm{Zn}-\mathrm{Cu}$ フェライト)の実験データも含めてプロットした. スヌーク積はフェライトの種類によらず，磁束密度と比例関 係にあることが分かる．またこの図より，いくつかの Li-Zn フェライトは比較的大きなスヌーク積を持つ事が分かった.

最後に，金属板で裹打ちをした単層型電磁波吸収体への応

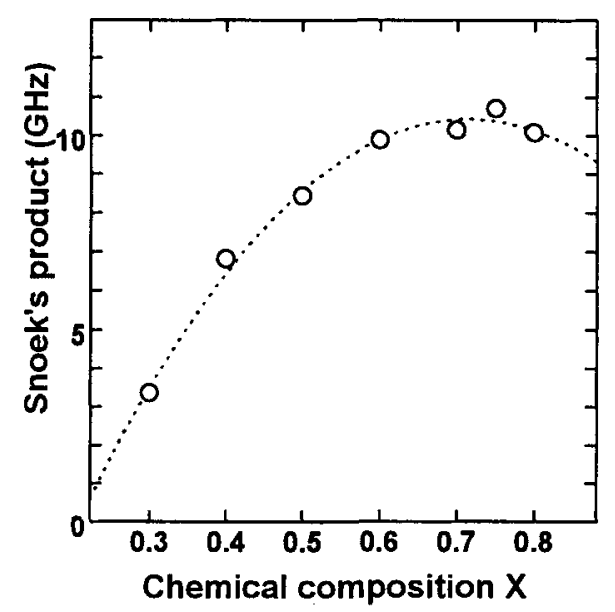

Fig.3 The variation of Snoek's product value versus the chemical composition of polycrystalline $\mathrm{Li}-\mathrm{Zn}$ ferrite, $\mathrm{Li}_{0.5 x} \mathrm{Zn}_{1-x}$ $\mathrm{Fe}_{2+0.5 x} \mathrm{O}_{4}$.

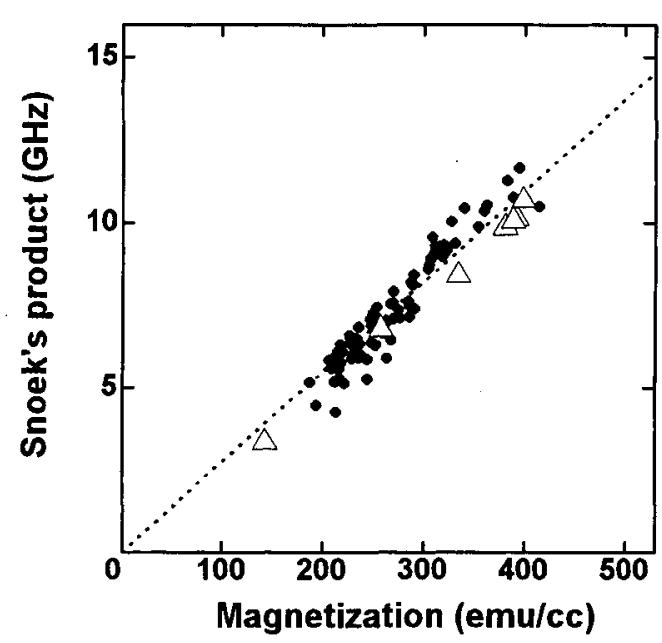

Fig.4 The variation of Snoek's product value with the magnetization flux for various polycrystalline ferrites: $\mathrm{Li}-\mathrm{Zn}$ ferrite (open triangle) and the other ferrite studied in the previous paper (small dot). The solid line is an extrapolation of the experimentally obtained values.
用を考える. 反射係数 $\Gamma(\omega)$ は以下のように表される.

$$
\Gamma(\omega)=20 \log \left|\left[Z(\omega)-Z_{0}\right] /\left[Z(\omega)-Z_{0}\right]\right| .
$$

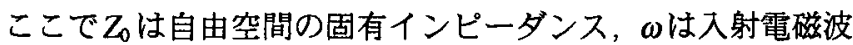
の角周波数, $Z(\omega)$ は電磁波吸収体の固有インピーダンス( 入 カインピーダンス)である.この $Z(\omega)$ は以下のように与えら れる。

$$
Z(\omega)=Z_{0}(\mu / \varepsilon)^{1 / 2} \tanh \left[j(\omega d / c)(\varepsilon \mu)^{1 / 2}\right] .
$$

ここで, $c$ は真空中での電磁波の進行速度, $d$ は吸収体の厚さ， $\varepsilon$ 亡 $\mu$ はそれぞれ電磁波吸収体の複素誘電率と複素透磁率であ る. 式(4)と (5)，及び実験で得られた複素誘電率と複素透磁 率の值を用いて，吸収特性を評価すること，および最適の整 合厚さを求めることができる.Li-Znフェライトを用いた電磁 波吸収体の特性を Fig.5 と Table 1 に示す. Table 1には，吸収 の中心周波数, 整合厚さに加えて, 反射係数が $-20 \mathrm{~dB}$ 以下と なる周波数帯域も示した. その結果, $100 \mathrm{MHz}$ から $1 \mathrm{GHz} の$ 周波数領域の比較的広範围の吸収体が得られることが分かっ た. 中心周波数は $150 \mathrm{MHz}$ から $850 \mathrm{MHz}$ の値をとり，Xの増 加とともに增加， $X=0.75$ で最大值をとり，その後減少した 整合厚さは，Xの增加とともに $5.5 \mathrm{~mm}$ から $3.0 \mathrm{~mm}$ と隇少し， 最小値となった後增加した．この吸収特性の変化はインピー ダンスの整合条件を考えることで説明できる. 入カインピー ダンスは，吸収体の厚さ $d$ が入射する電磁波の波長 $\lambda$ に比べ て十分に小さい時, 次のように近似できる.

$$
Z(\omega)=Z_{0} j(\omega d / c) \mu .
$$

大きな吸収が得られる周波数帯では，透磁率の虚数部が実数 部に比べて十分大きいので，更に以下のように近似できる.

$$
Z(\omega)=Z_{0} \omega d \mu^{\prime \prime} / c .
$$

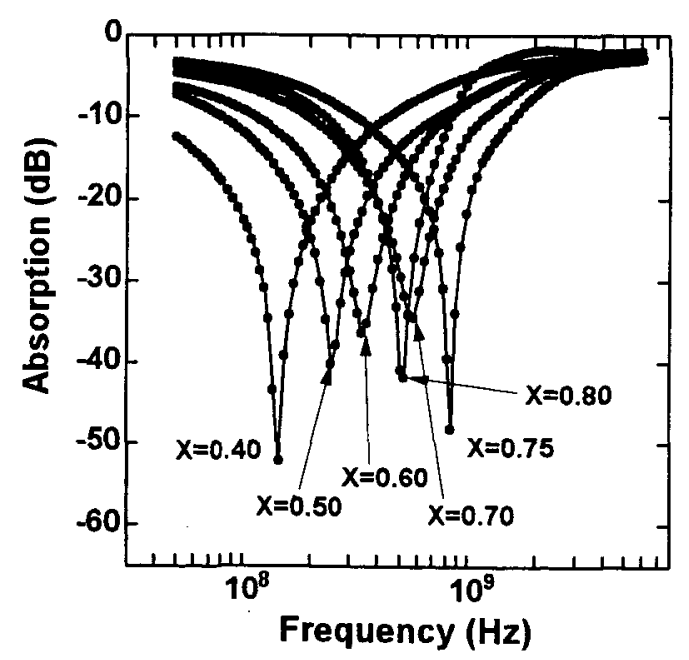

Fig.5 The electromagnetic wave absorption spectra of the single layered absorbers using the polycrystalline $\mathrm{Li}-\mathrm{Zn}$ ferrite, $\mathrm{Li}_{0.5 x} \mathrm{Zn}_{1-x} \mathrm{Fe}_{2+0.5 x} \mathrm{O}_{4}$. 
Table 1 The center frequency, the matching thickness and the absorption band for the polycrystalline $\mathrm{Li}-\mathrm{Zn}$ ferrite single layered absorbers.

\begin{tabular}{cccc}
\hline $\begin{array}{c}\text { Composition } \\
X\end{array}$ & $\begin{array}{c}\text { Matching Thickness } \\
(\mathrm{mm})\end{array}$ & $\begin{array}{c}\text { Center Freq. } \\
(\mathrm{MHz})\end{array}$ & $\begin{array}{c}\text { Absorp. Band } \\
(\mathrm{MHz})\end{array}$ \\
\hline 0.4 & 5.5 & 150 & $90-220$ \\
0.5 & 4.5 & 250 & $170-360$ \\
0.6 & 4.0 & 340 & $240-480$ \\
0.7 & 3.5 & 550 & $390-750$ \\
0.75 & 3.0 & 850 & $650-1000$ \\
0.8 & 4.0 & 530 & $400-650$ \\
\hline
\end{tabular}

ここで, 透磁率の虚数部は, 静的スピン磁化率の寄与のみを 考えると次のように表される.

$$
\mu^{\prime \prime}=K_{\mathrm{sp}} \omega_{\mathrm{sp}} \omega /\left(\omega_{\mathrm{sp}}{ }^{2} \omega^{2}\right) .
$$

さらに，透磁率の虚数部が実数部に比べて十分大きい周波数

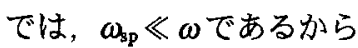

$$
Z(\omega)=Z_{0} d K_{\mathrm{sp}} \omega_{\mathrm{sp}} / c .
$$

即ち，スヌーク樌 $K_{\mathrm{sp}} \omega_{\mathrm{sp}}$ の大きなものほざ単位厚さあたりの 入カインピーダンスが大きくなり, 空間の固有インピーダン ス $Z_{0}$ と整合させるための厚さdが薄くなることを示している. 吸収体の整合厚さは，スヌーク樌の值を值接反映しているも のであることが分かった.

\section{4 結 論}

多結晶 $\mathrm{Li}-\mathrm{Zn}$ フェライトを固相反応法で作製し，複素透磁 率スペクトルを評価した. 透磁率の絶対值はLi-フェライトの 含有率とともに減少し，逆に共鳴周波数は高周波数側にシフ トした．得られた複素透磁率スペクトルを，数值計算を用い て磁化回転成分と磁壁移動成分に分倣することができた．磁 化回転成分より，Li-フェライトの含有率の增加とともに, 静 的スピン磁化率は減少しスピン共鳴周波数は高周波数側にシ フトした. スヌーク糟に対応する静的スピン磁化率とスピン
共鳴周波数の糟は，磁化に比例する事が分かった．高周波数 領域では磁化回転成分の奇与が極めて大きくなり，スヌーク 積は多結晶フェライトを用いた単層電磁波吸収体のような高 周波デバイスのよい指標となることが示された.

\section{文献}

1) G.T.Rado: "Magnetic spectra of ferrites", Rev. Mod. Phys., 25 (1953)81-89.

2) D.Polder and J.Smit: "Resonance phenomena in ferrites", Rev. Mod. Phys., 25(1953)89-90.

3) J.Smit and H.P.J.Wijn: Ferrites, Phillips Technical Library, Eindhoven, The Netherland, (1959).

4) J.L.Snoek: "Dispersion and absorption in magnetic ferrites at frequencies above one megacycle", Physica XIV, 4(1948)207-217.

5) T.Nakamura and T.Tsutaoka: "Low temperature sintering in $\mathrm{Ni}$ $\mathrm{Zn}$-Cu ferrite", Proceedings of $4^{\text {th }}$ International Conference on Electroceramics and Applications, (1994) 1149-1154.

6) T.Nakamura: "Low-temperature sintering of $\mathrm{Ni}-\mathrm{Zn} \mathrm{Cu}$ ferrite and their permeability spectra", J. Magn. Magn. Mater., 168 (1996)285-291.

7) T.Nakamura: "Experimental study on high-frequency permeability in polycrystalline $\mathrm{Ni}-\mathrm{Zn}, \mathrm{Mg}-\mathrm{Zn}$ and Ni-Zn-Cu ferrites", J. Appl. Phys., 88(2000)348-353. 